\title{
A REDEFINITION OF STONEMYIA \\ (DIPTERA: TABANIDAE) AND DESIGNATION \\ OF A NEW GENUS, PEGASOMYIA, FROM WESTERN NORTH AMERICA ${ }^{1}$
}

\author{
BY JOHN F. BURGER \\ Department of Entomology, \\ Nesmith Hall, University of New Hampshire, Durham, NH 03824
}

The genus Stonemyia was erected by Brennan (1935) to receive North American pangoniine species previously assigned primarily to non-Nearctic genera. Brennan placed species with bare eyes in Stonemyia s. str. For species with pilose eyes, at least in the male, he proposed the subgenus Pilimas. He did not, however, fix a type for Pilimas as required by the International Code of Zoological Nomenclature for genus-group names proposed after 1930. Pilimas, therefore, was unavailable. Pilimas was raised to the generic level by Philip (1941a) and Brennan subsequently (in Philip, 1941b) designated Diatomineura californica Bigot as the generotype of Pilimas in a note at the end of Philip's paper.

Structurally, both genera are very similar. Authors treating them have used primarily the presence or absence of a spur at the fork of the $\mathbf{R}_{4}$ and $\mathbf{R}_{5}$ veins and whether the eyes are bare or pilose. Neither of these characters, however, will absolutely separate these genera. Differences in the male and female genitalia have been used less frequently, perhaps because it is difficult to interpret structural differences observed.

Middlekauff and Lane (1980) summarized the morphological differences between Stonemyia and Pilimas, but did not mention genitalic differences. In their key, only the presence of the spur vein in Pilimas and its absence in Stonemyia is used to separate them. However, in their discussion of generic differences, they state that $5 \%$ of Pilimas californica (sic) lack the spur vein. They also mention that the eyes of Pilimas are "slightly" hairy and that those of Stonemyia are "practically bare."

'Scientific Contribution Number 1331 from the New Hampshire Agricultural Experiment Station.

Manuscript received b! the editor. November 27, 1984. 
In the most recent key to North American genera, Pechuman and Teskey (1981) used the absence of a spur vein on the fork of the $\mathbf{R}_{4}$ and $R_{5}$ veins, eyes bare in both sexes, the rounded female cerci and projecting process of the male gonostylus to separate Stonemyia from Pilimas. Except for genitalic differences, these characters will not always reliably separate these genera.

Mackerras (1955) discussed differences in the genitalia of Stonemyia and Pilimas. In females, Pilimas has a prominent apical lobe on the cerci (strongly bilobed in californicus) and the caudal ends of spermathecal ducts are membranous and unexpanded, while Stonemyia has cerci without an apical lobe and the caudal ends of the spermathecal ducts expanded and sclerotized. The gonostylus of Stonemyia has a peculiar outwardly projecting wing that is absent in Pilimas males.

The importance of male and female genitalia in generic separation of Stonemyia and related genera needs to be re-examined. Because tabanid genitalia are relatively simple and unspecialized, their structural features usually have not been useful for determining relationships below the level of tribe, but such features as are present should be examined critically at the generic level to determine if they can be used reliably to separate closely related genera.

Several years ago, J. R. Vockeroth of the Biosystematics Research Institute, Ottawa, discovered an interesting character in certain species of Stonemyia that appears to be unique in Tabanidae: the presence of a row of erect bristles on the ventral surface of the scutellum. I examined the North American species of Stonemyia in the collection of the U.S. National Museum and Stonemyia yezoense (Shiraki) from Japan and found that both sexes of all species possessed the bristles, although sometimes they were difficult to see because the base of the abdomen was closely appressed to the ventral area of the scutellum.

All other genera of Tabanidae in the USNM collection had the ventral surface of the scutellum bare, except both sexes of Pilimas californicus, which had strong bristles on the ventral surface of the scutellum as in Stonemyia species. The other two species of Pilimas ( $P$. abaureus Philip and P. ruficornis (Bigot) have the ventral surface of the scutellum bare and also differ from Stonemyia species in having the subscutellum conspicuously inflated, whereas in Stonemyia it is only slightly enlarged and much less conspicuous. The 
shape of the body of californicus is similar to the bee-like appearance of the Stonemyia species, the abdomen being stouter and more rounded, compared to Pilimas abaureus and ruficornis, whose abdomens are more slender and more nearly parallel-sided.

I therefore believe that californicus was mistakenly placed in the genus Pilimas and belongs instead in Stonemyia. Since Brennan designated californicus as the generotype of Pilimas, a new name is needed in which to place abaureus and ruficornis. Pegasomyia, new genus, is hereby proposed and contains these two species. The name is taken from Pegasus, the legendary flying horse of Greek mythology. Pilimas becomes a synonym of Stonemyia, NEW SYNONYMY. I designate Corizoneura ruficornis Bigot, 1892 as the generotype of Pegasomyia.

Stonemyia can be unequivocally separated from Pegasomyia by the presence of a row of bristles on the ventral surface of the scutellum and the relatively unexpanded subscutellum. Pegasomyia contains two western species, P. abaurea (Philip) and P. ruficornis (Bigot). Stonemyia in North America contains three eastern taxa: isabellina (Wiedemann), rasa (Loew) and tranquilla tranquilla (Osten Sacken), and three western taxa: californica (Bigot), tranquilla fera (Williston) and velutina (Bigot).

Six Palaearctic species have been placed in Stonemyia: yezoense (Shiraki), enokizonoi (Ouchi), hispanica (Krober), caucasica (Krober), tigris (Bigot) and bazini (Surcouf) (=chekiangensis (Ouchi)) (Moucha, 1976; Leclercq and Olsufjev, 1975). Stonemyia yezoense is a well-known Japanese species and has bristles beneath the scutellum as do the North American species. St. caucasica has well-developed ocelli and could be a Stonemyia species but this needs to be confirmed. The type male of St. enokizonoi, collected from Yaku Island off the southern coast of Japan, is thought to have been destroyed in Shanghai, China during World War II (Hayakawa, personal communication). It is very close to St. yezoense and may be conspecific with it. Study of hispanica by Schacht and Portillo (1982) revealed that it is a species of Philoliche (Ommatiosteres), not Stonemyia. Chainey (1983) provided a complete description and discussion of $P$. hispanica. It seems unlikely that tigris should be placed in Stonemyia since Bigot mentions in his original description that ocelli are absent, whereas they are welldeveloped in all known Stonemyia species. It is possible that tigris 
may also prove to be a species of Philoliche. Moucha (1976) listed bazini as a species of Philoliche, but this is unlikely since Surcouf (1922) described it as having well-developed ocelli and posterior cells of the wing wide open. Leclercq and Olsufjev (1975) list it in Stonemyia, but this should be confirmed by examination.

Thus, in the Palaearctic Region, only yezoense has been definitely confirmed as belonging in Stonemyia, but bazini and caucasica may also belong there.

\section{ACKNOWLEDGEMENTS}

I wish to thank John Chainey, British Museum (Natural History) and H. Hayakawa, Hokkaido National Agricultural Experiment Station, Japan for their information on Palaearctic taxa included in this study; G. B. Fairchild, University of Florida, L. L. Pechuman, Cornell University and H. J. Teskey, Biosystematics Research Institute, Ottawa for their suggestions and critical review of this paper; D. Chandler, University of New Hampshire, for reviewing an earlier draft of this manuscript.

\section{SUMMARY}

Pegasomyia, new genus, is proposed to replace the name Pilimas, the generotype of which belongs in the genus Stonemyia. Pegasomyia contains two California species, abaurea (Philip) and ruficornis (Bigot), the last of which is designated as generotype of Pegasomyia. A row of bristles on the ventral surface of the scutellum of Stonemyia species will separate them from Pegasomyia species which lack such bristles.

\section{Litheraturi: Cithid}

Brenan, J. M.

1935. The Pangoniinae of Nearctic America (Tabanidae, Diptera). Univ. Kansas Sci. Bull. 32: 249-401.

CuAini:y, J. E.

1983. Afrotropical Tabanidae (Diptera): The genus Philoliche Wiedemann, subgenus Ommatiosteres Enderlein. Ann. Natal Mus. 25: 453-474.

Li:ChercQ, M. \& N. G. Ol.suFJeV

1975. Catalog des Tabanidae (Diptera) Palearctiques. Bull. Ann. Soc. r. belge. Ent. 111: 2536. 
Mackerras, I. M.

1955. The classification and distribution of Tabanidae (Diptera). Il. History: Morphology; Classification: Subfamily Pangoniinae. Austral. J. Zool. 3: 439-511.

Middiekaulf, W. W. and R. S. Lane:

1980. Adult and immature Tabanidae (Diptera) of California. Bull. Calif. Ins. Survey, 22: 1-99.

Moucha, Joser

1976. Horse-flies (Diptera:Tabanidae) of the world. Synoptic catalogue. Acta ent. Mus. nat. Prague, Suppl. 7, 319 pp.

Piciluman, L. L. \& H. J. Theskey.

1981. Chapter 31, Family Tabanidae. In Manual of Nearctic Diptera. Research Branch, Agriculture Canada Monograph, No. 27, Volume 1, pp. 463-478.

PIIII.IP, C. B.

1941a. Comments on the spur-specific categories of Nearctic Tabanidae (Diptera). Can. Ent. 73: 1-14.

194lb. Notes on the Neacrtic Pangoniinae (Diptera, Tabanidae). Proc. Entomol. Soc. Wash. 43: 113-130

Schacit, W. \& M. Portilio

1982. Hybomitra (Mouchaemyia) tamujosoi sp. n. eine neue Bremsenart aus Spanien, nebst einen Anhang zu Stonemyia hispanica (Krober, 1921) und Tahanus bromius var. flavofemoratus Strobl, 1909 (Diptera, Tabanidae). Entomofauna 3: 161-174.

SuRCOUH, J.-M.-R.

1922. Dipteres nouveaux ou peu connus. Soc. ent. France 91: 237-244. 

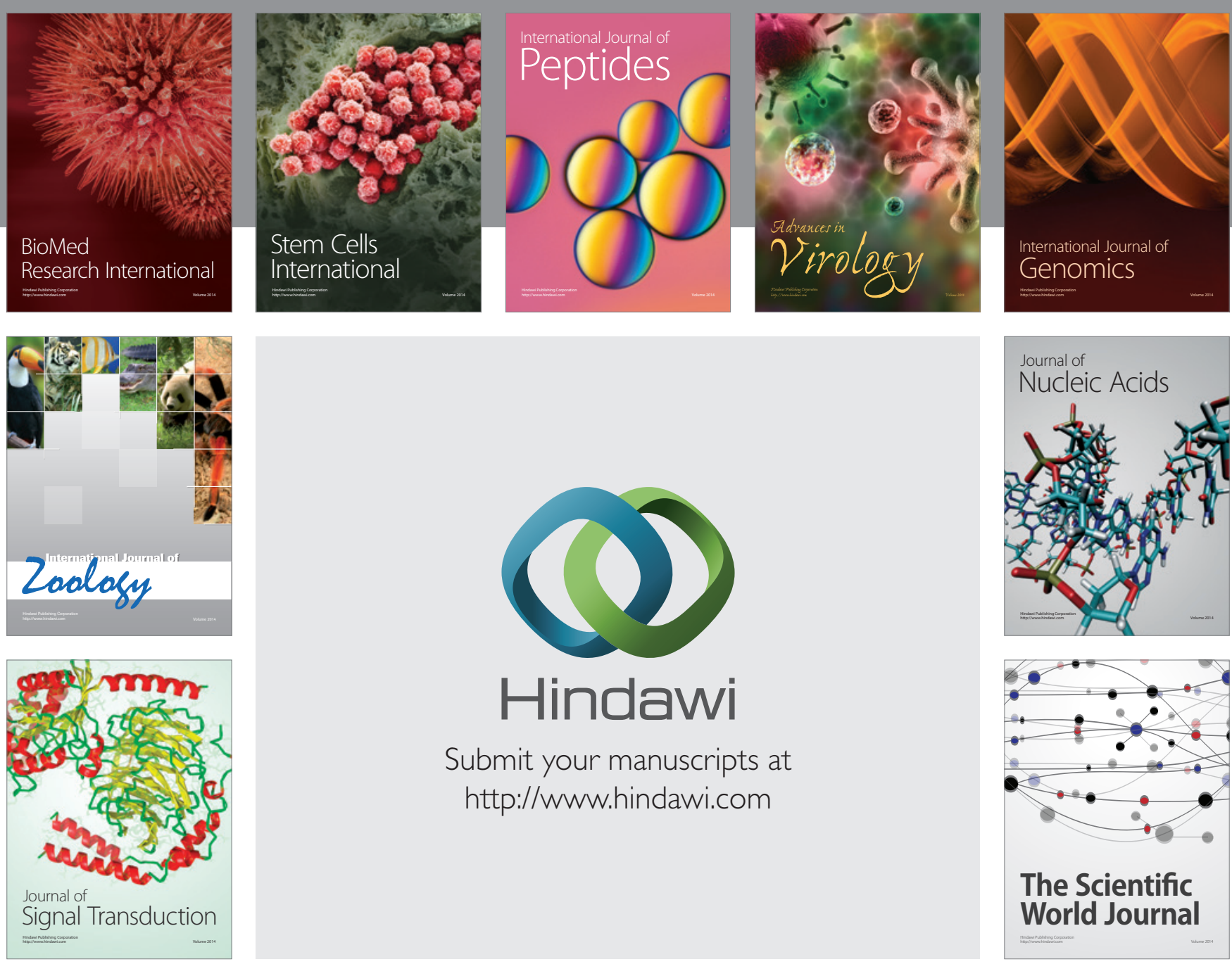

Submit your manuscripts at

http://www.hindawi.com
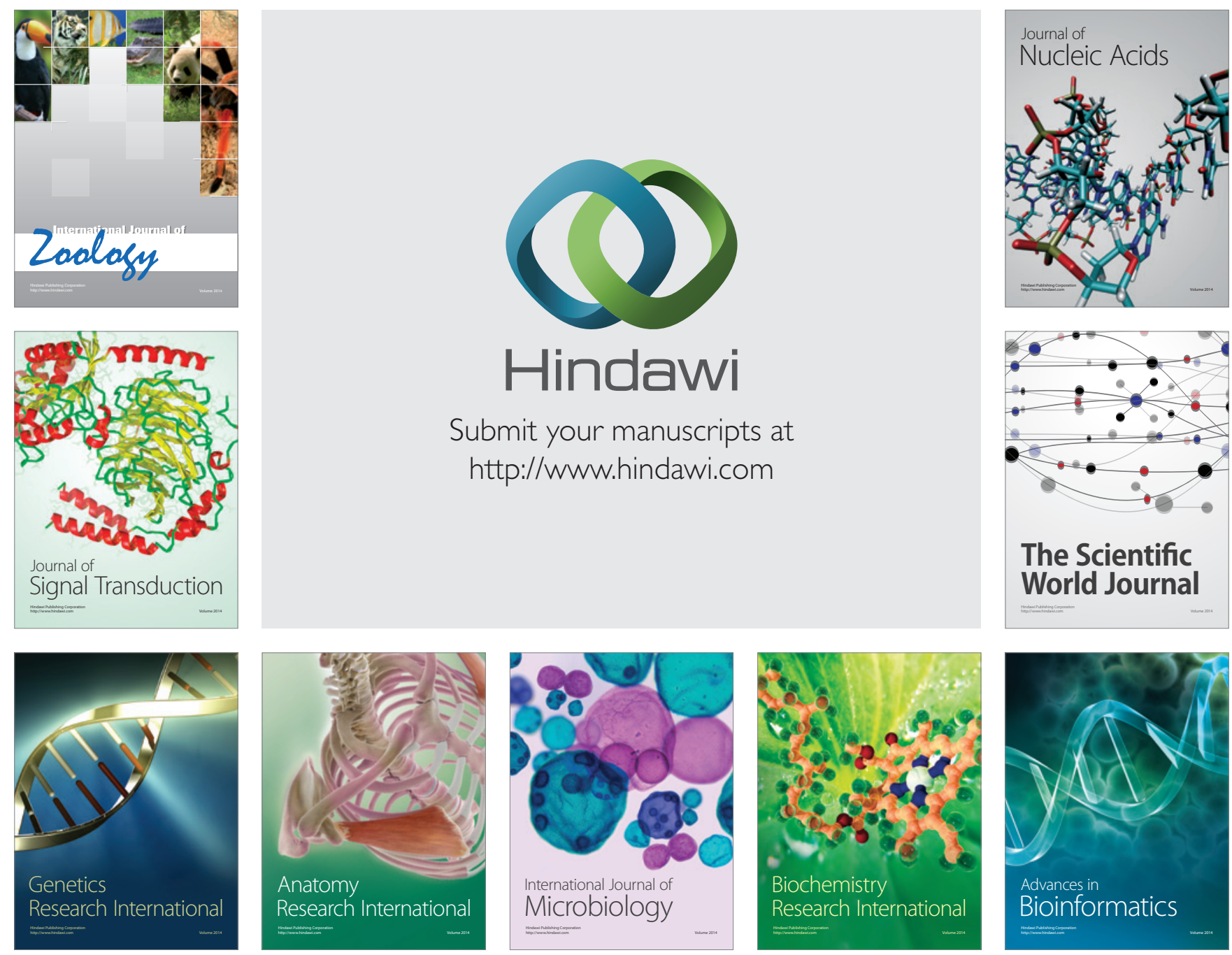

The Scientific World Journal
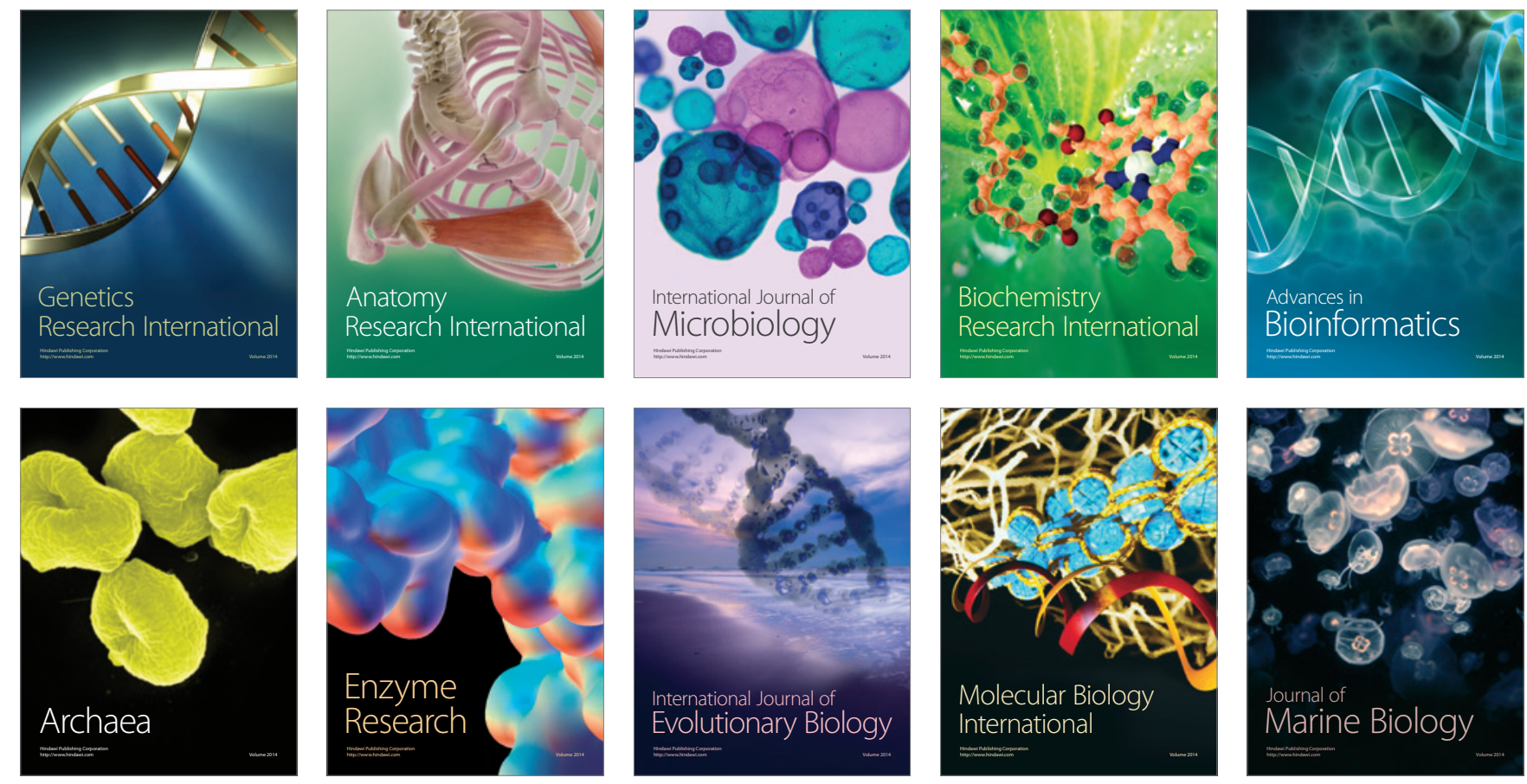